Hispania, 2019, vol. LXXIX, n. o 263, septiembre-diciembre, págs. 639-668 ISSN: 0018-2141, e-ISSN: 1988-8368, https://doi.org/10.3989/hispania.2019.015

\title{
El liderazgo militar en la Castilla del siglo $\mathrm{XV*}$
}

\author{
Ekaitz Etxeberria Gallastegi ${ }^{1}$ \\ Universidad del País Vasco \\ ekaitz.etxeberria@ehu.eus
}

RESUMEN: El objetivo de este artículo es analizar un aspecto descuidado por la historiografía española, el liderazgo militar en la Castilla del siglo XV en el contexto europeo. La documentación administrativa no resulta útil, manejaré como alternativa las fuentes narrativas, con especial atención a las crónicas regias y particulares. Organizaré la información en tres bloques temáticos relacionados con aspectos culturales, sociales y puramente militares: la formación militar, el acceso a los puestos de mando y su ejercicio. El examen demuestra que, a pesar de que para las capitanias de frontera se tenía en cuenta la veteranía y la pericia, los mecanismos de acceso al liderazgo estaban profundamente condicionados por la estructura social, quedando los más relevantes reservados a la alta nobleza. Las posibles disfunciones derivadas de un sistema militar que extrae a sus líderes del escalafón más alto se intentan paliar mediante una formación teórico-práctica que se emprende desde la niñez y que busca preparar a la nobleza para la tarea de ejercer el caudillaje militar. Con todo, la ausencia de una estructura de mando estable tenía un impacto directo en su ejercicio, provocando que los líderes con experiencia se vieran reducidos a persuadir e inspirar.

* Este trabajo se ha desarrollado en el marco de una ayuda para contratos predoctorales para la formación de doctores (ref. BES-2014-068717), financiada por el Ministerio de Economía y Competitividad del Gobierno de España. Además, se inscribe en el proyecto de investigación financiado por el Ministerio de Ciencia, Innovación y Universidades: «De la lucha de bandos a la hidalguía universal. Transformaciones sociales, políticas e ideológicas en el País Vasco (siglos XIV-XVI)», HAR2013-44093-P; y del Grupo de Investigación del Gobierno Vasco «Sociedad, poder y cultura (siglos XIV-XVIII)», IT-896-16. Agradezco a Francisco García Fitz y Fernando Arias la ayuda prestada en la revisión y mejora del texto.

1 ORCID iD: https://orcid.org/0000-0001-6428-2105.

Copyright: (C) 2019 CSIC. Este es un artículo de acceso abierto distribuido bajo los términos de una licencia de uso y distribución Creative Commons Reconocimiento 4.0 Internacional (CC-BY 4.0) 
PALABRAS CLAVE: nobleza; Castilla; guerra; liderazgo; crónicas; siglo XV.

\section{Military leadership in fifteenth-century Castile}

ABSTRACT: The aim of this paper is to analyse a neglected aspect of Spanish historiography regarding military leadership in fifteenth-century Castile set against a European background. As the administrative documentation is not useful, I will refer to alternative narrative sources, paying special attention to royal and private chronicles. I will organize the information into three thematic blocks related to cultural, social and purely military aspects: military training, access to command posts and leadership practice. The paper shows that, although seniority and expertise were taken into account for frontier captaincies, the mechanisms of access to leadership were deeply conditioned by social structure, with the most relevant command posts reserved for the upper nobility. There is an attempt to alleviate potential dysfunctions derived from a military system that draws its leaders from the highest ranks by means of a theoretical-practical training that is undertaken from childhood and seeks to prepare the nobility for the task of exercising military leadership. However, the absence of a stable command structure had a direct impact on leadership practice, meaning that the role of experienced leaders was reduced to persuading and inspiring.

KeY words: Nobility; Castile; Warfare; Leadership; Chronicles; 15th Century.

CÓMO CITAR ESTE ARTÍCULO/CITATION: Etxeberria Gallastegi, Ekaitz, «El liderazgo militar en la Castilla del siglo XV», Hispania, 79/263 (Madrid, 2019): 639-668. https://doi.org/10.3989/hispania.2019.015.

En 1449, los habitantes de Requena y Utiel se apresuraron a defenderse de una cabalgada aragonesa que había penetrado en sus tierras. Los castellanos situaron sus fuerzas en un paso estrecho, cometiendo la imprudencia de abandonar la tierra alta al enemigo. No fue el único error que los conquenses cometieron: sin amedrentarse ante la evidente desventaja, atacaron el cerro en el que estaban posicionados los aragoneses, resultando la contraofensiva un contundente fracaso castellano. Las crónicas no dudan en culpar de la derrota al hecho de que los aragoneses gozaban de «la buena ordenança de su capitán e de las ventajas que tenían», mientras que los castellanos «yvan sin capitán que a todos podiese mandar» ${ }^{2}$. Dieciséis años más tarde, los castellanos que guarnecían Nodar salieron a correr cerca de la villa portuguesa de Moura. Los portugueses, dirigidos por el almirante del reino, salieron en su persecución. El

\footnotetext{
${ }^{2}$ CARRILLO DE HUETE, 2006: 510-511. ROSELL, 1953: 661.
} 
líder luso intentó que los suyos atacaran ordenados pero, excitados por la superioridad numérica, acometieron en desorden y fueron derrotados por el hecho de que, según Diego de Valera, los castellanos tenían «capitanes estrenuos» ${ }^{3}$. Ambos casos ejemplifican, aunque tal vez de manera extrema, la importancia de que las huestes contaran con un líder militar que, además, debía ser efectivo, capaz de controlar a los hombres y guiarlos hacia la victoria. Las Siete Partidas (c. 1265) ya señalaban que, si no estaban bien acaudillados, muchos podían ser desbaratados por pocos ${ }^{4}$. Por tanto, como en todas las épocas históricas, en el «cuatrocientos» castellano también se valoraba la necesidad de un comandante eficaz y exitoso. La importancia del liderazgo emana con claridad de las fuentes, pero contrasta con la escasa atención que la historiografía moderna ha prestado a ese fenómeno.

En general, el liderazgo militar en la Europa medieval ha sido poco estudiado y, en tales ocasiones, se ha hecho de modo tangencial. De acuerdo con Lawrence W. Marvin, el mando bélico en el «largo siglo XII» no ha sido tomado en consideración debido a que se ha comparado con las edades antigua y moderna, una afirmación que podría aplicarse a todo el periodo medieval ${ }^{5}$. En realidad, hasta hace pocas décadas, la guerra medieval era considerada como un fenómeno en el que la táctica y, sobre todo la estrategia, brillaban por su ausencia ${ }^{6}$. Por ejemplo, Charles Oman, decimonónico pionero en el estudio de la guerra medieval, se negaba a reconocer apenas algún vestigio de competencia en el mando de tropas a los generales del medievo. Aun así, aceptaba que los suizos y los comandantes ingleses de la Guerra de los Cien Años mostraban habilidades genuinamente tácticas y estratégicas ${ }^{7}$. También Hans Delbrück compartía las reservas de Oman, pero únicamente admitía trazas de genio militar en los suizos ${ }^{8}$.

A la reticencia de los llamados «autores clásicos», se debe sumar el hecho de que hasta la renovación de la Historia Militar en la segunda mitad del siglo $\mathrm{XX}$, los estudios específicos sobre liderazgo estuvieron íntimamente relacionados con la historia de las batallas, plasmándose en relaciones de generales exitosos elaboradas siempre según criterios contemporáneos 9 . Incluso en obras influyentes como La máscara del mando, del reconocido historiador militar

3 VALERA, 1927: 20-21.

${ }^{4}$ SÁNCHEZ-ARCILLA, 2004, Segunda Partida, Título XXIII, Ley XI.

${ }^{5}$ Considera que la naturaleza de las fuentes, la ausencia de ejércitos profesionales o tácticas elaboradas y la nula comprensión de los objetivos militares medievales serían las razones por las que se ha obviado su estudio. MARVIN, 35/3 (Sídney, 2016): 152-176.

${ }^{6}$ Una buena síntesis sobre el devenir de la historia militar medieval, puede encontrarse en GARCÍA FITZ, 1998: 21-56; 2014: 17-52.

7 OMAN, 1953: 145; 1991, vol. 2.

8 DELBRÜCK, 1982.

${ }^{9}$ LIDDELL HART, 1946: 97-106. 
John Keegan, el liderazgo medieval es completamente obviado ${ }^{10}$. Quizá, como sostiene Craig Taylor, los comandantes medievales han sido subestimados porque las fuentes pocas veces dejan observar los procesos según los cuales se desarrollaban los planes de campaña ${ }^{11}$.

A mediados del siglo XX, autores renovadores como Jan F. Verbruggen, Raymond C. Smail, y John Beeler comenzaron a considerar cuestiones de mando militar en relación con las prácticas bélicas ${ }^{12}$. Otro historiador destacado, John Gillingham, trabajó las figuras de Guillermo el Conquistador y Ricardo Corazón de León desde una perspectiva estratégica ${ }^{13}$. Por su parte, John France dedicó un capítulo al ejercicio del mando en su libro sobre la guerra en la cristiandad occidental en la época de las Cruzadas y Michael Prestwich hizo lo propio en su obra sobre la guerra y ejércitos ingleses en la Edad Media $^{14}$. En los últimos años, los estudios sobre el mando militar han proliferado, lidiando con los comandantes franceses o escoceses del bajo medievo o tratando figuras destacadas, como el rey Balduino IV de Jerusalén (1161-1185) o Luis VII de Francia (1120-1180) ${ }^{15}$. La eclosión de estos trabajos ha abierto la puerta al análisis del rol militar de las mujeres, cuyo máximo exponente sería Juana de $\mathrm{Arco}^{16}$. También se han realizado estudios de carácter interdisciplinar analizando el papel del liderazgo militar femenino desde una perspectiva de género ${ }^{17}$.

Estos estudios apenas han tenido eco en el ámbito castellano, donde la cuestión ha sido abordada por Francisco García Fitz en dos artículos sobre el Cid y Fernando el Católico ${ }^{18}$. Otros autores como Manuel Rojas, L. J. Andrew Villalon o Donald J. Kagay, han realizado aportaciones puntuales, pero no existe ningún trabajo sobre liderazgo militar que englobe Castilla en su conjunto y la enmarque en un contexto europeo ${ }^{19}$. Mi propósito en este ensayo es destacar la importancia y connotaciones sociales del mando militar en los ejércitos castellanos durante el siglo XV, una fase en la que estaban aún en vías de profesionalización. Para alcanzar ese objetivo, y ante la ausencia de registros

${ }^{10}$ KEEGAN, 2015.

11 TAYLOR, 2013: 238.

12 VERBRUGGEN, 1997. SMAIL, 1996. BEELER, 3 (Cambridge, 1963): 1-10.

${ }^{13}$ GILLINGHAM, 1992b: 143-160; 1992a: 194-207.

${ }^{14}$ FRANCE, 1999: 139-149. PRESTWICH, 1996: 159-183.

15 ROGERS, 2 (Woodbridge, 2004): 89-110. MACDONALD, 2012: 255-282. HAMILTON, 1998: 119-130. HOSLER, 2018: 11-28. MARVIN, 2018: 29-49.

${ }_{16}$ DeVRIES, 1999.

17 HAY, 2010.

18 GARCÍA FITZ, 2000: 383-418; 2016: 47-71.

19 ROJAS, 20 (Sevilla, 1993): 499-522; 22 (Sevilla, 1995): 497-532. VILLALON, 8 (Woodbridge, 2010): 131-54. KAGAY, 2013: 63-84. El liderazgo nobiliario, a pesar de haber sido obviado en sus aspectos militares, ha sido estudiado en relación con su vertiente sociocultural. Véase MARTÍNEZ SOPENA, 2013. 
administrativos antes de la Guerra de Granada que permitan abordar la cuestión desde la perspectiva de la organización militar, recurriré como alternativa a las fuentes narrativas a fin de esbozar una imagen panorámica sobre el liderazgo militar en la Castilla del siglo XV. Así, las crónicas y biografías particulares de los reinados de Juan II, Enrique IV y los Reyes Católicos permiten estudiar el mando militar ${ }^{20}$. Utilizaré también diversos tratados, corpus jurídicos y obras que permiten asomarse a la teoría que se escondía detrás de la práctica.

Analizaré el liderazgo militar en la Castilla del «cuatrocientos» a través de las tres fases vitales por las que debía pasar todo noble que aspirara a comandar tropas: la formación militar, el acceso a posiciones de mando y, por último, la práctica del liderazgo en sí mismo. El estudio conjunto de estos tres aspectos interrelaciona cuestiones culturales, sociales y militares. Solo así se pueden comprender las limitaciones que padecían los ejércitos castellanos y las respuestas que generaron para superarlas.

\section{Formación Militar de La NOBLEZa}

En la Edad Media, el poder social y político estaba en manos de una élite aristocrática que tenía la guerra como función social. Los miembros del estamento nobiliario recibían una educación que cubría diferentes aspectos, entre los que destaca el militar ${ }^{21}$. Más allá de aprender a manejar las armas, los nobles también cazaban y participaban en torneos, dos ejercicios que servían como entrenamiento para la guerra en la medida en que ayudaban a perfeccionar la equitación y el uso de la lanza ${ }^{22}$. Pero estas actividades servían para su formación como guerreros, no para su preparación como líderes. Por lo tanto, ¿dónde obtenían los conocimientos necesarios para dirigir tropas?

Los libros que pululaban por la Castilla del «cuatrocientos», constituían, sin duda, un apoyo importante ${ }^{23}$. Dejaré de lado obras con clara vocación moral, como el Árbol de las batallas de Honoré Bouvet - traducido por Diego de Valera para el condestable Álvaro de Luna (1390-1453) ${ }^{24}$ - y me centraré en las exclusivamente militares. Entre ellas destaca la obra de Sexto Julio Frontino

${ }^{20}$ Sobre el uso de las fuentes cronísticas para estudiar la Historia Militar Medieval, véase DeVRIES, 2 (Woodbridge, 2004): 1-15.

${ }^{21}$ BECEIRO, 2007: 113, 129, 145-151.

${ }^{22}$ MONTEIRO, MARTINS y FARIA, 43 (Ámsterdam, 2017): 128-129. GARCÍA FITZ, 19 (Barcelona, 1989): 274-275.

${ }_{23}$ Philippe Contamine señalaba que «las bibliotecas de los hombres de guerra (de hecho, las de los nobles de cierto rango que hubieran ostentado responsabilidades militares) resultan a menudo muy instructivas». CONTAMINE, 1984: 271.

${ }^{24}$ BOUVET, 2008. 
(c. 40-103), como atestiguan los diversos autores que lo citan directamente ${ }^{25}$. Además, hay constancia de que el marqués de Santillana, Iñigo López de Mendoza (1398-1458), y el tercer conde de Benavente, Alfonso de Pimentel († 1461), contaban con una copia en sus bibliotecas ${ }^{26}$. Por otro lado, una traducción de las Estratagemas se encontraba en la biblioteca que el primer conde de Haro, Pedro Fernández de Velasco (1399-1470), mandó donar al hospital que acababa de fundar en Medina de Pomar en el año $1455^{27}$.

Con todo, el autor más celebrado fue Flavio Vegecio Renato ${ }^{28}$. Se sabe que el famoso De Re Militari tuvo una amplia difusión en Castilla, siendo referenciado en las Partidas, en la obra de Gil de Zamora y por Don Juan Manuel ${ }^{29}$. Este clásico de la literatura militar había sido traducido al castellano a principios del siglo XV por el fraile dominico Alfonso de San Cristóbal a instancia del rey Enrique III ${ }^{30}$. La presencia del autor romano en las bibliotecas nobiliarias castellanas se constata sobre todo en época de los Reyes Católicos, como demuestra el ejemplar que poseía Alvar Pérez de Guzmán, señor de Orgaz († 1482), aunque previamente también se conocía, pues figura en el inventario de la biblioteca del conde de Haro ${ }^{31}$. Aun así, al ser uno de los autores más reconocidos, existían formas más «indirectas» de acercarse a la obra del tratadista romano. Precisamente la conocida obra de Egidio Romano - o Giles de Roma-De regimine principum, copia de Vegecio los apartados dedicados al arte bélico ${ }^{32}$. Este libro aparece inventariado en las bibliotecas de Iñigo López de Mendoza, Alfonso de Pimentel, Alvar Pérez de Guzmán y Fernando Álvarez de Toledo, primer conde de Oropesa $(\dagger 1504)^{33}$.

Junto con los tratados militares, también son registrados en los inventarios de las bibliotecas nobles distintas crónicas y obras históricas ${ }^{34}$. La nobleza

${ }^{25}$ Tal es el caso de Rodrigo Sánchez de Arévalo y Fernando del Pulgar, a los que tal vez podría sumarse Gómez Manrique y Juan de Mena. ROCA, 2010: 84-87.

${ }^{26}$ SCHIFF, 1905: 141-142. BECEIRO, 2007: 463.

27 LAWRENCE, 1 (Madrid, 1984): 1074.

${ }^{28}$ ALLMAND, 2011: passim.

29 GARCÍA FITZ, 19 (Barcelona, 1989): 271-274.

${ }^{30}$ FRADEJAS, 2014: 65-66. ROCA, 2010: 83.

31 BECEIRO y FRANCO, 12 (Sevilla, 1986): 296, 328. LAWRENCE, 1 (Madrid, 1984): 1110. ROCA, 2010: 83.

${ }^{32}$ ALLMAND, 2011: 105-111. FRADEJAS, 2014: 33. MONTEIRO, MARTINS y FARIA, 43 (Ámsterdam, 2017): 131.

33 SCHIFF, 1905: 209-211. BECEIRO, 2 (Madrid, 1982): 139. BECEIRO y FRANCO, 12 (Sevilla, 1986): 296, 331.

${ }^{34}$ Philipe Contamine destacaba que, a principios del siglo XV, Guichard Dauphin, señor de Jaligny, poseía diferentes crónicas, así como las obras de Tito Livio. Por otro lado, el inventario de libros (1497) de Bernard de Bearn, bastardo de Commenge, mostraba las crónicas de Jean Froissart, las Décadas de Tito Livio y el Jouvencel de Jean de Bueil. CONTAMINE, 1984: 271. Los autores franceses bajomedievales Pierre Bersuire, Jean Gerson y Philippe de 
encontraba en la lectura de estos textos, además de una satisfacción de su interés por los relatos guerreros de tiempos pasados, enseñanzas e ideas que podían poner en práctica en el campo de batalla. Aparecen crónicas castellanas en numerosas bibliotecas. Sin ánimo de realizar un listado exhaustivo - que puede ser consultado en los trabajos de Isabel Beceiro-, cabe mencionar las elaboradas por Pero López de Ayala ${ }^{35}$. También cuentan con obras históricas de autores clásicos que podían contribuir a la educación de los futuros líderes militares. En este sentido, los condes de Haro, Benavente y Oropesa así como el marqués de Santillana contaban con copias de la obra de Ayala y de las Décadas de Tito Livio, por citar solo una de las obras más relevantes ${ }^{36}$. Por último, las Siete Partidas son habitualmente citadas en los inventarios de las bibliotecas nobiliarias: aun no siendo obras didácticas, sí que destilan cierto afán educativo ${ }^{37}$. Así, de la Segunda Partida podían haber extraído enseñanzas de cómo dirigir las huestes, junto con descripciones de los rasgos que deberían definir al buen líder ${ }^{38}$.

Como se ha comprobado, la literatura susceptible de ser utilizada en la didáctica militar estaba muy presente. Ahora bien, el hecho de que tuvieran esos libros, no significa que los leyeran ${ }^{39}$. De hecho, no tenían por qué leerlo ellos mismos, bastaba con tener el libro. En la Segunda Partida se menciona que los caballeros debían formarse mediante la experiencia en tiempo de guerra, mientras que, en tiempo de paz, debían escuchar. La hora de comer era un momento propicio para que alguien leyera en alto las historias de los grandes hechos de armas del pasado. Asimismo, allí donde no había libros que leer, los caballeros ancianos se encargarían de impartir la lección. Incluso cuando no se podía dormir, se recomendaba ordenar que les leyeran ese tipo de obras ${ }^{40}$. La lectura en voz alta de crónicas y tratados era habitual también en la corte portuguesa: el cronista Gomes Eanes de Zurara escribió que, tras conquistar Ceuta en 1415, João I recomendó a sus hombres leer a Egidio Romano en la

Commynes enfatizaban el valor de leer crónicas e historias para aprender sobre guerra y estrategia. TAYLOR, 2013: 245.

${ }^{35}$ GARCÍA FITZ, 19 (Barcelona, 1989): 276. BECEIRO, 2 (Madrid, 1982): 141.

${ }^{36}$ LAWRENCE, 1 (Madrid, 1984): 1109-1110. BECEIRO, 2007: 462-63. BECEIRO у FRANCO, 12 (Sevilla, 1986): 331-335. SCHIFF, 1905: 402-403.

37 GARCÍA FITZ, 19 (Barcelona, 1989): 272. Dos copias aparecen listadas en las bibliotecas de los condes de Haro, Benavente y Oropesa. LAWRENCE, 1 (Madrid, 1984): 1110. BECEIRO, 2007: 467. BECEIRO y FRANCO, 12 (Sevilla, 1986): 333.

38 SÁNCHEZ-ARCILLA, 2004, Segunda Partida, Título XXIII, Leyes IV-XVI.

39 Rodríguez Velasco cree que la ausencia de glosas en el manuscrito indica que el marqués de Santillana no leyó a Frontino. RODRÍGUEZ, 1996: 85. Aun así, podía haber excepciones. Fernando del Pulgar informa de que el primer conde de Haro «aprendió letras latinas y dávase al estudio de corónicas e saber fechos pasados». PULGAR, 2007: 100.

40 SÁNCHEZ-ARCILLA, 2004, Segunda Partida, Título XXI, Ley XX. 
cámara real para que los cortesanos se familiarizaran con los secretos del arte militar $^{41}$.

Los escritores, traductores e intelectuales del medievo, tienden a enfatizar la importancia del aprendizaje bélico mediante la lectura. El célebre cronista Jean Froissart mencionaba en el prólogo de su obra que esta podía servir para animar a jóvenes caballeros. Precisamente son las crónicas, destinadas al consumo nobiliario, las que se presentan más a menudo como fuente de consejos sobre la ciencia o arte de la guerra ${ }^{42}$. Así lo demuestra un pasaje narrado por la Crónica de Juan II, cuando informa de la muerte de unos jóvenes caballeros en una escaramuza no exenta de imprudencia. De este suceso, acaecido en 1407, dice el cronista que «los mancebos deven tomar exemplo» ${ }^{43}$. Del mismo modo, el marqués de Cádiz fue capaz de tomar Medina Sidonia en 1473, en el marco de la guerra privada que lo enfrentaba con Enrique de Guzmán, debido a que la fortaleza no estaba protegida como debía. Diego de Valera señalaba que «sin duda, si este malaventurado alcayde oviera leydo la Segunda Partida, no pusiera en tan mal recabdo su honrra e su vida ${ }^{44}$.

Pedro Mártir de Anglería consideraba que aquel que se consagrara a la milicia debía estar bien instruido en los ejemplos de los antiguos en el momento de partir hacia la guerra, pues «¿quién niega que con la asidua lectura de la Historia los hombres se hacen cada día más prudentes? $\rangle^{45}$. La importancia de conocer los hechos históricos se muestra de forma evidente en las fuentes cronísticas, especialmente si se combate en el mismo lugar que aparece en las historias. Durante las fases previas del asedio a Antequera, en 1410, el infante Fernando juzgó necesario tomar una sierra que dominaba la villa, pues allí podría posicionarse un ejército de socorro venido a levantar el cerco «como diz que otra vez fizieron al rey don Alonso su bisabuelo, que diz que estovo sobre esta villa de Antequera, e le tomaron los moros esta sierra, e de tal modo daban acorro a la villa que entravan e salían quando querían, a que se ovo de alçar de sobre ella $\rangle^{46}$. La anécdota recuerda a la estratagema utilizada por Fernando de Aragón para entrar en Nápoles utilizando un acueducto, un subterfugio que se le

${ }^{41}$ MONTEIRO, MARTINS y FARIA, 43 (Ámsterdam, 2017): 131.

42 TAYLOR, 2013: 244-245. El cronista Andrés Bernáldez admitía que «las crónicas no se comunican entre las gentes comunes». BERNÁLDEZ, 1962: 24.

43 GARCÍA, 2017: 260-261.

${ }^{44}$ VALERA, 1941: 236-239. SÁNCHEZ-PARRA, 1991: 395-398. Valera es un autor que valora especialmente el aprendizaje a través lectura. En una de sus cartas enviadas a los Reyes Católicos durante la Guerra de Granada, recuerda a Fernando que leyendo crónicas de tiempos pasados descubrirá que batallas, asedios y cabalgadas son tres pilares básicos y complementarios para la consecución de la victoria en la guerra. BALENCHANA, 1878: 62-65.

${ }^{45}$ ANGLERÍA, 1953: 24.

46 GARCÍA, 2017: 384-385. 
ocurrió tras leer la Historia de las Guerras Góticas de Procopio ${ }^{47}$. En ambos casos, el conocimiento del terreno proporcionado por fuentes históricas resultó vital para el desarrollo de las operaciones.

La importancia de la formación teórica ha sido objeto de debate. Centrándome en el ejemplo de Vegecio, Contamine cree que su utilidad para un comandante medieval era limitada, debido a la ausencia de un ejército permanente y una estructura de mando rígida ${ }^{48}$. Tal vez por eso, la copia de la traducción de San Cristóbal que figura en la biblioteca del conde de Haro únicamente recoge el libro III del tratado romano, aquel dedicado a las batallas campales ${ }^{49}$. Una elección lógica, ya que, como señala García Fitz, las tácticas expuestas en el tercer libro «son lo suficientemente generales como para poder aplicarse a cualquier tipo de ejército» ${ }^{50}$. Aun así, Rodríguez Velasco cree que la lectura de Vegecio tan sólo confirmó a los nobles lo que ya sabían ${ }^{51}$. Si bien es cierto que la mayoría de consejos que se pueden encontrar en el autor romano pueden ser calificados de «sentido común», estos podían tener cierta utilidad ${ }^{52}$. No en vano Philippe de Mézières, hombre de guerra francés, recomendaba a los futuros líderes militares leer a Vegecio ${ }^{53}$. Del mismo modo, fue precisamente un caballero castellano el que recomendó a Carlos el Temerario, a partir de sus lecturas «vegecianas», que construyera una grúa durante el sitio de Neuss en $1474-75^{54}$.

Michael Mallet, el gran experto en las guerras mercenarias de la Italia bajomedieval, creía que lo más probable era que un capitán del «cuatrocientos» hubiera aprendido el arte de la guerra a través de un condotiero establecido y no mediante los libros ${ }^{55}$. Por mi parte, comparto lo postulado por Craig Taylor. El autor inglés defiende que es imposible saber hasta qué punto los aristócratas medievales buscaban desarrollar su inteligencia táctica y estratégica a través de la lectura en vez de mediante el tutelaje basado en la experiencia práctica y el consejo de guerreros veteranos ${ }^{56}$. Esta opinión ya fue expresada por Isabel Beceiro y Philippe Contamine, quienes señalaron que la guerra conllevaba un

47 CONTAMINE, 1984: 270.

48 CONTAMINE, 1984: 267.

49 FRADEJAS, 2014: 111. ROCA, 2010: 83.

50 GARCÍA FITZ, 19 (Barcelona, 1989): 273.

${ }^{51}$ RODRÍGUEZ, 1996: 85. Roca señala que la influencia real de Vegecio y Frontino en la didáctica europea debe considerarse con sus limitaciones, ROCA, 2010: 75.

${ }_{52}$ Para un exhaustivo estudio sobre la influencia y utilidad de la obra del autor romano, véase ALLMAND: 2011.

53 TAYLOR, 2013: 253

${ }^{54}$ CONTAMINE, 1984: 267. No debe extrañar, por tanto, que el prólogo a la traducción castellana de las Estratagemas de Frontino señale que, tras la lectura de la obra, «serán los capitanes de agora informados et aperçebidos, así con discreción commo con enxemplo de la providencia antigua». ROCA, 2010: 91.

55 MALLET, 1974: 176-177.

56 TAYLOR, 2013: 231-236. 
aprendizaje de carácter práctico, transmitido de generación en generación ${ }^{57}$. En este punto es donde jugaba un papel realmente importante la figura del noble encargado de tutelar a los pupilos enviados a su casa, responsable de enseñar a los jóvenes aristócratas la capacidad de dominar, tanto en contextos sociales como militares. Es de suponer que la instrucción se impartía verbalmente. Geoffrey de Charney opinaba que las habilidades de liderazgo táctico y estratégico se aprendían mediante la experiencia, el tutelaje y la conversación con expertos $^{58}$.

Para el caso concreto de la Castilla del siglo XV, la obra Claros varones de Castilla, de Fernando del Pulgar, constituye una fuente excepcional. El variado repertorio de ejemplos contenidos en esta colección de biografías permite analizar una cuestión sobre la que, de otro modo, sería difícil arrojar algo de luz. Entre las figuras tratadas por Pulgar, una de las más destacadas es la del conde de Paredes y maestre de Santiago, Rodrigo Manrique (1406-1476), guerrero experimentado, ampliamente loado por las crónicas de su tiempo ${ }^{59}$. Manrique se esforzaba especialmente en que sus criados estuvieran perfectamente preparados para cuando entraran en batalla. Les contaba sus hechos de armas, sus anécdotas bélicas, discutía con ellos las diferentes formas de combatir y los entrenaba para la guerra ${ }^{60}$. Su propio hermano, el poeta Gómez Manrique, afirmaba haber «mamado en la leche» el ejercicio de las armas, pues desde su niñez estuvo «en la escuela de vno de los mas famosos maestros que, como vuestra merçed bien sabe, ouo en nuestro tienpos, que fue mi señor e mi hermano don Rodrigo Manrique» ${ }^{61}$.

Otra de las grandes figuras de mediados del «cuatrocientos» castellano fue el marqués de Santillana, adalid del Renacimiento, que unía su interés por las armas con su amor a las letras. De nuevo, al igual que en el caso de Rodrigo Manrique, Fernando del Pulgar presenta a un İnigo de Mendoza preocupado por la formación bélica de sus pupilos. Hablaba con los caballeros y escuderos de su casa sobre cómo ordenar las batallas, disponer los campamentos y atacar o defender las fortalezas, deleitándose en esas conversaciones «por la grand abituación que en ella tovo en su mocedad». Le interesaba también que la formación teórica estuviera complementada con aquella de índole más práctica, que «supiesen por experiencia lo que le oían decir por doctrina». Para ello, organizaba justas y otros ejercicios de guerra en su casa, a fin de que su gente estuviera preparada llegado el momento ${ }^{62}$.

\footnotetext{
57 BECEIRO, 2 (Madrid, 1982): 143-144. CONTAMINE, 1984: 271.

58 TAYLOR, 2013: 240.

59 VALERA, 1941: 279. PALENCIA, 1973, vol. 2: 144.

60 PULGAR, 2007: 154-157.

61 RODRÍGUEZ, 1996: 84.

62 PULGAR, 2007: 105.
} 
La fase de formación, iniciada en torno a los siete años, concluía a los catorce o quince ${ }^{63}$. Aun así, en la Edad Media, la vida militar se vivía en primera persona ${ }^{64}$. La formación marcial no se completaba hasta que participaban en una campaña militar, su bautismo de fuego ${ }^{65}$. Esta podía ser una forma temeraria de aprender un oficio tan peligroso como el de las armas, que podía traducirse en un elevado número de muertes prematuras derivadas de la inexperiencia e imprudencia juvenil ${ }^{66}$. Aun así, esta fase de la vida de un noble no tardaba en llegar y era preferible pasar por ello cuanto antes, para ir acumulando experiencia ${ }^{67}$. Los ejemplos de jóvenes nobles iniciándose en el oficio de las armas son diversos. Pero Niño tenía quince años cuando escaramuzó bajo los muros de Gijón en 1394, mientras que su hijo «tomó sus armas contra sus contrarios» a los catorce ${ }^{68}$. El cronista y banderizo Lope García de Salazar tenía dieciséis años la primera vez que empuñó su ballesta en combate ${ }^{69}$. Rodrigo Ponce de León, futuro marqués de Cádiz, comenzó algo más tarde: tenía entre diecisiete y dieciocho años en la batalla del Madroño, en $1462^{70}$.

La edad en la que se comenzaba la carrera militar no estaba predeterminada y dependía de una serie de factores externos, aunque el más importante era que hubiera guerras en las que participar. El ejemplo de los monarcas castellanos cuatrocentistas resulta ilustrativo. Juan II tuvo su primera experiencia genuinamente bélica en 1429, a los veinticuatro años de edad. Asimismo, no luchó en su primera batalla campal hasta los veintiséis - La Higueruela, 1431- $\mathrm{Su}$ hijo, el futuro Enrique IV, dio sus primeros pasos en el campo de Marte a la edad de veinte años participando en su primera batalla, la de Olmedo, en $1445^{71}$. Fernando el Católico constituye un caso ciertamente inusual pues es sin duda el rey más belicoso y con mayor bagaje militar de entre los que se sentaron en el trono castellano en el siglo XV. El hecho de que fuera aragonés no es ningún elemento de distorsión, en la medida en la que las pautas de aprendizaje eran similares para toda la nobleza - y realeza - europeas. La proliferación de conflictos durante la vida del Rey Católico le permitió tomar su primer contacto

${ }^{63}$ SHAHAR, 1992: 211.

64 TAYLOR, 2013: 239.

${ }^{65}$ FRANCE, 1999: 140.

${ }^{66}$ ROJAS, 20 (Sevilla, 1993): 513.

${ }^{67}$ CONTAMINE, 1984: 273.

${ }^{68}$ DÍAZ DE GAMES, 2005: 243-244, 528.

${ }^{69}$ VILLACORTA, 2015: 878.

${ }^{70}$ CARRIAZO, 2003b: 159. BERNÁLDEZ, 1962: 11.

${ }^{71}$ La familia real inglesa se mostró más precoz. Eduardo de Woodstock, «el Príncipe Negro», combatió en la batalla de Crecy (1346) a la edad de dieciséis años; su hermano, Juan de Gante, participó en el combate naval de Winchelsea (1350), con tan solo diez. El vencedor de la batalla de Agincourt (1415), Enrique V, tenía once años cuando participó en una campaña militar por primera vez, combatiendo en la batalla de Shrewsbury (1403), a los diecisiete. GOODMAN, 2006: 128-129. 
con la guerra a la temprana edad de nueve años, cuando en 1461 quedó encerrado en la Girona asediada por el conde de Pallars. Aun así, su primera experiencia puramente militar no llegó hasta 1465 , con casi trece años de edad, cuando comandó la retaguardia del ejército real en la batalla de Calaf. Al año siguiente acompañaba a su padre en los asedios de Tortosa y Amposta y, en 1467, combatió contra las tropas angevinas en Viladomat, donde fue derrotado y casi hecho prisionero ${ }^{72}$.

En conclusión, la combinación de tutelaje, ejercicio físico y lectura preparaban parcialmente a la clase noble para su rol militar. Este periodo de instrucción no se vería completo hasta que realizaran los primeros hechos de $\operatorname{armas}^{73}$. Así era como la nobleza castellana aprendía las habilidades de mando, en un proceso que no se diferenciaba del seguido por el resto de la nobleza europea. Con todo, tras instruirse en el liderazgo de una hueste había que llegar a dirigirla.

\section{Mecanismos de aCCESO AL Liderazgo}

Inglaterra, Aragón o Navarra venían desarrollando desde mediados del siglo XIV ejércitos profesionales que respondieran a las necesidades derivadas de las campañas militares exteriores que llevaron a cabo ${ }^{74}$. Sin embargo, ello no supuso un cambio en las estructuras de mando. Únicamente tras la creación del primer ejército permanente de la Europa feudal, el francés en 1445, se generaron unas estructuras de mando estables y más complejas que, sin embargo, siguieron dirigidas por la nobleza ${ }^{75}$. La situación no era diferente en la Castilla del siglo $\mathrm{XV}$, donde coexistieron las obligaciones feudales con el pago de salarios, manteniéndose una estructura de mando que puede calificarse de elemental. Habrá que esperar a la aparición del ejército permanente en 1493 para comenzar a observar cadenas de mando más estructuradas que permitían la realización de carreras específicamente militares ${ }^{76}$. Hasta entonces, el liderazgo militar estaba íntimamente conectado con el sociopolítico.

El único liderazgo verdaderamente indiscutible recaía sobre los hombros del monarca, a quien le correspondía el mando supremo de la hueste. En una cultura marcial como la de la aristocracia europea, se esperaba que un rey

72 PULGAR, 2008, vol. 2: 403. PALENCIA, 1998, vol. 2: 305-306. MAS, 1993: 377. SUÁREZ, 2004: 26-29.

${ }^{73}$ La posibilidad de mostrarse como valientes guerreros es parte no sólo del proceso de aprendizaje de la nobleza, sino también de su función social, de su liderazgo sobre aquellos de baja cuna. Asimismo, supone el reconocimiento de sus habilidades por sus homólogos.

${ }^{74}$ BELL, CURRY, KING y SIMPKIN, 2013. SÁIZ, 2008. LAFUENTE, 2014. FERNÁNDEZ DE LARREA, 2013.

${ }^{75}$ CONTAMINE, 1972: 399-487.

${ }^{76}$ ARIAS, 2018: 96-97.

Hispania, 2019, vol. LXXIX, nº 263, septiembre-diciembre, págs. 639-668, ISSN: 0018-2141, e-ISSN: 1988-8368 https://doi.org/10.3989/hispania.2019.015 
dirigiera sus fuerzas en la guerra. Fernando el Católico cumplió con la premisa, liderando en persona el ejército real durante la Guerra de Sucesión Castellana y la Guerra de Granada ${ }^{77}$. Sin embargo, la inseguridad sobre la capacidad militar y política de Juan II y Enrique IV les empujó a delegar el mando en líderes más capaces o de su confianza entre miembros de la alta nobleza. Durante la batalla de La Higueruela en 1431 y la primera batalla de Olmedo en 1445, el mando de la hueste de Juan II correspondió a Álvaro de Luna ${ }^{78}$. En el segundo de los encuentros campales que tuvieron lugar a las puertas de la villa vallisoletana, en el año 1467, el mando de la hueste de Enrique IV fue ejercido por los nobles que le acompañaban, siendo Pedro de Velasco, futuro conde de Haro, quien dirigió la batalla real mientras que el rey permaneció en retaguardia ${ }^{79}$.

Por debajo de la autoridad real existían una serie de cargos palatinos. Para acceder a los mismos el patronazgo regio se tornaba indispensable. Tal vez donde mejor se observe sea en el cargo de condestable, creado en 1382 y patrimonializado por los Velasco en $1473^{80}$. El más célebre de entre los condestables del siglo XV, Álvaro de Luna, era hijo ilegítimo de una familia perteneciente a la nobleza aragonesa, que había ascendido gracias su cercanía a Juan II. Consiguió el título en 1423 y su primera acción militar no tuvo lugar hasta 1429, por lo que resulta evidente que no recibió el cargo debido a sus méritos bélicos. El siguiente en el cargo, Miguel Lucas de Iranzo, constituye un ejemplo de ascenso exclusivamente ligado al patronazgo regio, que en esta ocasión no solo no estaba vinculado a su experiencia militar, sino que tampoco lo estaba a su extracción social. De los cuatro que ejercieron el oficio de condestable a lo largo del periodo que nos ocupa, Iranzo es el único que no tenía un origen noble, pues su padre era un campesino.

Otro de los cargos con aparentes prerrogativas militares de la Castilla del «cuatrocientos» eran los adelantados, sobre cuyos hombros descansaba la defensa de la frontera granadina. Sin embargo, para las fechas de este estudio, sus funciones habían disminuido considerablemente. Estos cargos acabaron siendo monopolizados por dos prominentes familias con arraigo patrimonial sobre los territorios de su mandato: los Ribera convirtieron el adelantamiento de la frontera en dignidad hereditaria, mientras que los Fajardo hicieron lo propio con el de Murcia ${ }^{81}$.

Más allá del patronazgo o la condición hereditaria de algunos oficios, la idea de que los méritos y la habilidad debían ser tenidos en cuenta para la

77 GARCÍA FITZ, 2016: 53-58.

${ }^{78}$ CHACÓN, 1940: 134, 168. GARCÍA DE SANTA MARÍA, 1891: 292. CARRILLO DE HUETE, 2006: 463-464. ROSELL, 1953: 628.

${ }^{79}$ ENRÍQUEZ DEL CASTILLO, 1994: 276. VALERA, 1941: 126.

${ }^{80}$ El cargo era hereditario también en Inglaterra. PRESTWICH, 1996: 171.

${ }^{81}$ LADERO, 4 (Madrid, 1984): 447. JIMÉNEZ, 1993: 151. 
asignación de algunos cargos militares ya estaba presente en las Partidas $^{82}$. Ahora bien, ¿existía algún medio de ascenso por méritos o los criterios de acceso al mando eran exclusivamente sociopolíticos? Esta es, sin duda, una pregunta difícil de responder utilizando únicamente fuentes narrativas. Sin embargo, el estudio de las capitanías de frontera puede arrojar luz sobre la cuestión. Estos mandos militares se designaban al abrirse hostilidades con algún reino vecino y su función consistía en defender sectores concretos de la frontera y realizar incursiones y ataques de forma tanto independiente como conjunta. Disponían de un número concreto de lanzas, aunque también poseían potestad para convocar tropas en el territorio al que estaban asignados, pudiendo castigar a aquellos que desobedecieran sus órdenes ${ }^{83}$. En definitiva, era un cargo temporal similar al utilizado con otros nombres en Inglaterra - warden - y Portugal - fronteiro - ${ }^{84}$.

Tomaré como ejemplo la guerra de 1429-30 contra Aragón y Navarra y la guerra contra Granada de 1430-39. Se trata de dos conflictos consecutivos que permiten distinguir pautas de asignación de las capitanías y comprobar el grado de veteranía de los seleccionados. En 1429, la frontera con los reinos navarro y aragonés se dividió en cuatro sectores, cada uno con su capitán. Tras la firma de las treguas de Majano y el inicio de un nuevo enfrentamiento contra el enemigo musulmán en 1430, la frontera granadina se dividió también en cuatro sectores. En julio de 1431, después de la victoria en la batalla de La Higueruela, la configuración de las capitanías fronterizas sufrió una reestructuración que se mantendría hasta el final de la guerra, contando únicamente con dos sectores: el arzobispado de Sevilla por un lado y los obispados de Jaén y Córdoba por otro ${ }^{85}$. En total, al menos once individuos diferentes sirvieron como capitanes de la frontera en la década que media entre 1429 y 1439: de ellos, dos eran condes, dos maestres de órdenes militares, dos adelantados mayores y uno mariscal. Los restantes cuatro eran titulares de señorío, aunque conseguirían títulos nobiliarios: tres condados y un marquesado ${ }^{86}$. Por tanto

82 SÁNCHEZ-ARCILLA, 2004, Segunda Partida, Título XXIII, Ley VI.

${ }^{83} \mathrm{La}$ de los capitanes de la frontera es una figura que precisa de estudio, ya que no se puede reseñar más que el trabajo de López de Coca sobre Fernando Álvarez de Toledo. LÓPEZ DE COCA, 33/2 (Barcelona, 2003): 643-666.

${ }^{84}$ SIMPKIN, 2008: 35-36. MONTEIRO, 1998: 139-143.

${ }^{85}$ GARCÍA DE SANTA MARÍA, 1891: 312. Es difícil realizar un seguimiento exhaustivo de los capitanes de la frontera, pues las noticias recogidas en las crónicas son dispersas y, en ocasiones, incompletas. Véase el anexo final.

${ }^{86}$ Pedro de Velasco conseguiría el Condado de Haro en 1430, Fernando Álvarez de Toledo, el de Alba en 1439 y Pedro Álvarez de Osorio, el de Trastámara en 1445. Por su parte, Iñigo López de Mendoza llegaría a ser conde del Real de Manzanares, en 1445 y marqués de Santillana, en 1448.

Hispania, 2019, vol. LXXIX, nº 263, septiembre-diciembre, págs. 639-668, ISSN: 0018-2141, e-ISSN: 1988-8368 https://doi.org/10.3989/hispania.2019.015 
cabe afirmar que en Castilla, al igual que en Portugal, la alta nobleza monopolizaba las capitanías de frontera ${ }^{87}$.

Con todo, el propio carácter temporal del cargo acabó impidiendo su patrimonialización. Su ejercicio era rotatorio, lo que dificultaba que líderes poco capaces actuaran durante largos periodos. Cuando Juan II relevó a varios capitanes fronterizos en 1430 y 1432, lo hizo, según Alvar García de Santa María, «porque los trabajos é también las honras de estas Capitanías se repartiesen por los caballeros é Grandes del reino» ${ }^{88}$. La propia frase indica que el mando fronterizo estaba reservado a la nobleza del reino. No obstante, queda la duda de si entre la aristocracia la selección se realizaba según criterios meritocráticos. Es cierto que gran parte de los capitanes designados en 1430 eran caballeros de la casa de Álvaro de Luna, lo que nos llevaría a pensar en el patronazgo también en esta ocasión ${ }^{89}$. Aun así, la experiencia podría haber sido tenida en cuenta, pues aquellos capitanes lo suficientemente mayores como para haber participado en las campañas granadinas de Fernando de Antequera lo habían hecho ${ }^{90}$. Por otro lado, hay indicios que podrían apuntar a un reconocimiento de la pericia, ya que, según Pulgar, tanto Fernando Álvarez de Toledo, en 1429, como Iñigo López de Mendoza, en 1437, accedieron al cargo debido a que el rey supo de su habilidad ${ }^{91}$. Además, se observa que no todos los capitanes fueron sustituidos. Tal es el caso de Diego Gómez de Ribera, que ostentó la capitanía hasta su muerte en Álora en $1434^{92}$. Es lógico en la medida en la que era el adelantado mayor de Andalucía y sus tierras estaban muy cerca de la frontera, un criterio que gozaba de cierta consideración en Inglaterra ${ }^{93}$. Posiblemente habría que pensar también en términos de eficacia: Ribera había cosechado una serie de éxitos, derrotando a un gran número de granadinos en una doble celada en 1430 y venciendo en batalla campal en $1432^{94}$. Aun así, la mayoría de los capitanes fueron sustituidos en algún momento, aunque el tiempo de servicio era variable: el futuro conde de Alba ejerció como capitán en tres ocasiones,

${ }^{87}$ MARTINS y MONTEIRO, 2018: 229.

88 GARCÍA DE SANTA MARÍA, 1891: 199, 371.

89 CHACÓN, 1940: 119-120.

${ }^{90}$ GARCÍA, 2017: 382-383, 394, 397, 448-449. ROSELL, 1953: 286, 297, 317, 320 328, 341. JIMÉNEZ, 1993: 151-152. Debido a la escasez de campañas bélicas en el periodo comprendido entre 1410 y 1429 , muchos nobles castellanos no tuvieron oportunidad de ganar experiencia militar. En la Guerra de Granada se observa que los capitanes de la frontera que ocuparon el cargo a partir de 1482 eran veteranos como el duque de Nájera, el maestre de Santiago o el marqués de Cádiz. En esta ocasión el mando también se ejerció de forma rotatoria. STEWART, 5 (Los Ángeles, 1975): 228.

91 PULGAR, 2007: 107, 116.

${ }^{92}$ GARCÍA DE SANTA MARÍA, 1891: 399-400.

93 SIMPKIN, 2008: 41-42.

${ }^{94}$ CARRILLO DE HUETE, 2006: 71-73. GARCÍA DE SANTA MARÍA, 1891: 275-278, 364-366.

Hispania, 2019, vol. LXXIX, nº 263, septiembre-diciembre, págs. 639-668, ISSN: 0018-2141, e-ISSN: 1988-8368 https://doi.org/10.3989/hispania.2019.015 
realizando un servicio total de siete años, mientras que Pedro Álvarez de Osorio únicamente lo hizo por uno.

Hasta ahora he examinado el caso del alto mando y de los mandos autónomos. Pero existían también mandos subalternos que articulaban la cadena de liderazgo desde los comandantes de cada ejército a los combatientes. Me referiré a continuación a la selección de los líderes de cada una de las batallas en las que se articulaba el cuerpo principal de un ejército a la hora de desplegarse en el campo de la lid.

En principio, además de ejercer el mando superior, el rey casi siempre comandaba una batalla, como hizo Juan II en La Higueruela en el año 1431 y Olmedo en 1445, o Fernando el Católico en Toro en $1476^{95}$. El condestable tenía, entre las dignidades inherentes a su oficio, el honor de dirigir la vanguardia, cosa que Álvaro de Luna hizo en La Higueruela y Olmedo. El resto de batallas quedaban en manos de miembros de la alta nobleza. En La Higueruela las seis batallas fueron lideradas por tres condes, el maestre de Calatrava, el condestable y el propio monarca ${ }^{96}$. En la primera batalla de Olmedo, el ejército de Juan II de Castilla estaba dividido en cinco batallas, comandadas por el condestable Álvaro de Luna, el rey Juan II, el príncipe Enrique, el maestre de Alcántara y el conde de Alba compartiendo mando con Íñigo López de Mendoza ${ }^{97}$. Algo similar a lo ocurrido en la segunda batalla de Olmedo de 1467, donde el liderazgo del ejército enriqueño correspondió, de nuevo, a la alta nobleza. El mando subalterno fue ejercido de forma algo diferente en la hueste rival del infante Alfonso, dado que la mayoría de los Grandes que le apoyaban se encontraban ausentes en el momento de la batalla. Por ello, fueron los capitanes de los nobles afines al infante quienes tuvieron que dirigir los escuadrones ${ }^{98}$.

En definitiva, los mecanismos de acceso al liderazgo en la Castilla del «cuatrocientos» dependían, fundamentalmente, del origen social de los sujetos y del patronazgo regio, cuando aquellos cargos no eran hereditarios. Ambos aspectos debían estar debidamente equilibrados, de lo contrario se podían generar distorsiones en el sistema, como ejemplifica el nombramiento de Miguel Lucas de Iranzo como condestable en 1458. La experiencia se vuelve un requisito más relevante en el caso de los mandos independientes, como son las capitanías de frontera. Aunque la extracción social de los capitanes era aristocrática, las fuentes narrativas castellanas parecen sugerir que la experiencia y la veteranía

${ }^{95}$ CHACÓN, 1940: 134, 168. GARCÍA DE SANTA MARÍA, 1891: 292. CARRILLO DE HUETE, 2006: 463-464. ROSELL, 1953: 628. PULGAR, 2008, vol. 1: 208-209. VALERA, 1927: 68.

${ }^{96}$ Eran los condes de Niebla, Ledesma y Castañeda. CHACÓN, 1940: 134. GARCÍA DE SANTA MARÍA, 1891: 292.

97 CARRILLO DE HUETE, 2006: 463-464. ROSELL, 1953: 628. CHACÓN, 1940: 168.

${ }_{98}$ ENRÍQUEZ DEL CASTILLO, 1994: 276. VALERA, 1941: 126. PALENCIA, 1998: 422-423.

Hispania, 2019, vol. LXXIX, nº 263, septiembre-diciembre, págs. 639-668, ISSN: 0018-2141, e-ISSN: 1988-8368 https://doi.org/10.3989/hispania.2019.015 
eran tenidas en cuenta a la hora de designar al titular de las capitanías fronterizas. Las Partidas ya señalaban que un caudillo debía ser elegido por su linaje, poderío o sabiduría. Sin embargo, las dos primeras no valían de nada si se desconocían las vicisitudes del ejercicio del mando ${ }^{99}$. El sistema contaba, por tanto, con sus propios mecanismos correctores para depurar a los nobles poco capaces y valerse de aquellos especialmente hábiles. De ahí la duración variable del servicio y el hecho de que de los seis nobles que sirvieron en la guerra contra Navarra y Aragón, cinco repitieron en el siguiente conflicto.

\section{La PRÁCTICA DEL LIDERAZGo}

El liderazgo de los ejércitos cuatrocentistas castellanos, al igual que el del resto de huestes medievales y al contrario que en las fuerzas armadas modernas, no iba acompañado de una autoridad incuestionable. El ejercicio del mando estaba sometido a una dinámica y a unas tensiones propias, derivadas en buena medida de los mecanismos sociales de reclutamiento y organización. Esta fragilidad inherente a la cadena de mando podía dar lugar a situaciones en las que individuos de un mismo espectro social pudieran negarse a obedecer las órdenes o instrucciones de alguien jerárquicamente superior, pero con un estatus social inferior.

Posiblemente, el ejemplo más evidente sea el de Miguel Lucas de Iranzo, condestable del reino. Los Hechos del Condestable Iranzo inciden en varias ocasiones en el poco amor que «el conde de Ledesma y los otros priuados del rey» le tenían. En 1464, el conde de Ledesma y futuro duque de Alburquerque, Beltrán de la Cueva, quiso comprobar que las batallas del condestable estuvieran bien ordenadas. Ese mismo año, sumó una nueva afrenta pues intentó arrebatar la posición de vanguardia a Iranzo — dignidad inherente a la condestablía - en el ejército real que escaramuzó con los granadinos en la Vega de Granada ${ }^{100}$. Incluso sin necesidad de que un completo advenedizo de origen campesino fuera quien ejerciera la posición de mando, podían darse este tipo de indisciplinas. Tras la toma de la villa navarra de Laguardia, en 1430, Diego de Zúñiga solicitó auxilio al obispo de Calahorra — también un Zúñigaque, a su vez, avisó al entonces capitán de ese sector de la frontera, Pedro de Velasco. Velasco montó en cólera al ser informado, pues no se debían llevar a cabo acciones bélicas sin su consentimiento. Tal fue la ira, que no quiso enviar gente a reforzar a los que estaban en Laguardia, aunque finalmente cedió ante la insistencia de los mensajeros solicitando socorro. Llegados Velasco y el obispo a la villa, el prelado, en un audaz golpe de mano, se hizo cargo de la situación, impidiendo al capitán de la frontera la entrada en Laguardia,

\footnotetext{
99 SÁNCHEZ-ARCILLA, 2004, Segunda Partida, Título XXIII, Leyes V-VI.

100 CARRIAZO, 2009: 192-197.
} 
alegando no estar bajo su capitanía ${ }^{101}$. Ambos casos ilustran un problema de autoridad, jurisdicción y disciplina, una cuestión endémica con la que tuvieron que lidiar los comandantes castellanos del siglo XV. Un líder medieval tenía que ser un maestro de la persuasión ${ }^{102}$.

El mando supremo del ejército también requería de capacidad negociadora, en la medida en que ni las decisiones estratégicas ni las tácticas emanaban únicamente del monarca, sino de las resoluciones adoptadas por el consejo del rey. Ante la negativa de Fernando de Antequera de abandonar el asedio de Setenil en 1407, la aristocracia allí presente no dudó en recordarle que no solo debía dejarse asesorar por ella, sino también «estar por el consejo de los que más acuerdan». Esto podía dar lugar a ciertas situaciones comprometidas para el comandante en jefe, especialmente si este no era el propio soberano. En esa misma campaña de 1407, el regente había tenido que claudicar ante esos mismos nobles, que durante la planificación estratégica le instaron a sitiar Setenil en vez de Ronda. El cronista esgrime dos razones por las que el de Antequera se vio obligado a ceder: «Porque si algún yerro se fiziese, por consejo de todos, que no se contase a él» y porque «ellos avían visto más de guerra que él, e avían mayor edad» ${ }^{103}$. Con el paso del tiempo, Fernando el Católico también acabó comprendiendo la utilidad de valerse de los consejos de guerreros experimentados. Así, en 1482 ignoró el consejo del marqués de Cádiz de no cercar Loja, lo que resultó un rotundo fracaso castellano. De nuevo en 1483, el maestre de Santiago no siguió las advertencias de este veterano de la frontera de Granada y dirigió una cabalgada al montañoso corazón de Málaga, también con desastrosas consecuencias. A partir de 1484, sin embargo, la voz de Rodrigo Ponce de León, líder de eficacia probada, fue tomando más peso en la elaboración de los planes de campaña ${ }^{104}$.

Confiar en el juicio de los más expertos debió de ser una práctica común. Diego de Valera escribió que, en las cuestiones bélicas, el rey debía valerse del consejo de caballeros experimentados sin menospreciar a los adalides y a los que conocen la tierra, afirmación similar al consejo que Guillaume de Machaut le dio a Carlos II de Navarra ${ }^{105}$. El veterano routier Rodrigo de Villandrado

${ }_{101}$ GARCÍA DE SANTA MARÍA, 1891: 184.

102 FRANCE, 1999: 149.

${ }^{103}$ En este caso, no se puede evitar pensar en un intento de eximir al de Antequera de la derrota que les deparó el asedio a la villa gaditana. De hecho, avanzada la narración, el de Antequera no duda en echar en cara a los nobles haberle forzado a atacar Setenil en vez de Ronda. GARCÍA, 2017: 234-235, 269.

${ }_{104}$ PALENCIA, 1973, vol. 3: 95, 100, 121, 141. VALERA, 1927: 147-148, 162, 182-183, 199-200. BERNÁLDEZ, 1962: 125, 155. CARRIAZO, 2003b: 209-210, 217, 237, 248. A la hora de justificar una derrota, ignorar los consejos de los entendidos se presenta como un recurso frecuente en la cronística. TAYLOR, 2013: 242.

105 BALENCHANA, 1878: 67. VALERA, 1927: 147-148. TAYLOR, 2013: 243-44. La serie de cartas enviadas por Valera evocan al cuaderno escrito por Juan Mathe de Luna a Sancho IV 
participó en el Consejo Real de Juan II, «especialmente de aquellas cosas que concernían a la guerra que por estonçes avía en sus reinos ${ }^{106}$. Con todo, resulta difícil creer que la experiencia era un requisito para participar en los consejos, especialmente si se tiene en cuenta que en los celebrados en diferentes reinados y fechas tan dispares como 1429 y 1482 estuvieron presentes varias personas con poca o ninguna relación con la guerra, como procuradores de las ciudades y villas, contadores mayores y «otros muchos cavalleros e doctores» ${ }^{107}$.

Pero más allá de la estrategia decidida en el Consejo del Rey, tal vez sea en el plano táctico donde se muestre de forma más evidente la necesidad de un liderazgo firme. En el campo de batalla, al comandante se le presentaba la elección de dirigir desde la retaguardia o combatir en primera línea. Ambas opciones acarreaban ventajas y desventajas. Una posición atrasada ofrecía una vista del campo de batalla y mayores facilidades de dirigir una reserva al lugar adecuado en el momento oportuno. Las crónicas portuguesas, en contraste con las castellanas, indican que Fernando el Católico era un «práctico guerrero» porque durante la batalla de Toro no comandó su batalla en persona y se alejó para ver cómo se desarrollaba la refriega ${ }^{108}$. Igualmente, el adelantado Diego Gómez de Ribera fue un líder que prefirió comandar desde la zaga. Tanto en la célebre doble celada que preparó en las cercanías de Colomera, en 1430, como en la batalla que lo enfrentó con los musulmanes en la Vega de Granada, en apoyo a la facción granadina favorecida por Juan II, en 1432, Ribera comandó la reserva táctica ${ }^{109}$.

Aun así, es sabido que, en la Edad Media, no había mucho que un líder pudiera hacer una vez iniciada la melé, salvo intervenir con la reserva ${ }^{110}$. Por ello los comandantes en jefe procuraban organizar sus tropas correctamente y establecer su cometido antes del enfrentamiento. En la batalla de La Albuera del año 1479, el maestre de Santiago, Alonso de Cárdenas, a la vista de los portugueses, «ordenó su gente de la forma que avia de yr e avisoles de lo que avian de facer» ${ }^{111}$. Del mismo modo, en los momentos previos a la batalla de La Higueruela, en 1431, Álvaro de Luna informó a las demás batallas que «quando

\footnotetext{
y María de Molina en 1294, en el que proponía un plan de acción para la toma de Algeciras. GARCÍA FITZ, 19 (Barcelona, 1989): 272.

106 PULGAR, 2007: 134. Parece que durante la guerra civil de 1465-67 no se mantenía ese criterio, pues Alonso de Palencia señala que al pasarse Pedro de Velasco, primogénito del conde de Haro, al bando enriqueño, fue aceptado en los consejos reales, «a pesar de no haber acaudillado tropas a ninguna expedición guerrera». PALENCIA, 1998, vol. 2: 418.

107 GARCÍA DE SANTA MARÍA, 1891: 44-47. VALERA, 1927: 148. En algunas repúblicas italianas eran común elegir comités especiales con poderes extraordinarios, para que discutieran cuestiones estratégicas con los comandantes militares. CAFERRO, 2005: 86.

108 PINA, 1977: 846.

109 CARRILLO DE HUETE, 2006: 71-73. GARCÍA DE SANTA MARÍA, 1891: 275-278, 364-366.

${ }^{110}$ MARVIN, 35/3 (Sídney, 2016): 176. ROGERS, 2007: 186-188.

111 OROZCO y PARRA, 1978: 406.
}

Hispania, 2019, vol. LXXIX, nº 263, septiembre-diciembre, págs. 639-668, ISSN: 0018-2141, e-ISSN: 1988-8368 https://doi.org/10.3989/hispania.2019.015 
él moviesse fiziesen aquello mismo», para atacar todos de forma coordinada y conjunta. A continuación, arengó a sus tropas, las posicionó correctamente e iba «avisando a cada uno en la guisa que avía de fazer»» ${ }^{12}$. En el cuerpo a cuerpo, las trompetas y los estandartes eran la única guía que tenían los hombres. Las cornetas podían tocar a avance y retirada, siendo especialmente relevantes al inicio de la batalla con el fin de organizar una acción conjunta ${ }^{113}$. Aun así, los símbolos visuales tenían especial relevancia pues, a pesar de que en el fragor de la batalla un caballero no vería más allá del enemigo, la visión vertical podía ser salvada por el estandarte. Se avanzaba cuando la enseña lo hacía y se retrocedía de la misma forma, pues siempre que esta se mantuviera en pie significaba que la batalla no estaba perdida ${ }^{114}$. Por ello, la forma más rápida y eficaz de concluir una batalla era derribando o apresando la divisa enemiga, como ocurrió en Jersey en el año 1406, en los dos enfrentamientos de Olmedo de 1445 y de 1467, o en Toro en el año $1476^{115}$.

La segunda forma de dirigir un ejército en batalla era en primera línea. Las Siete Partidas señalan que los caudillos debían ser «esforzados para cometer las cosas peligrosas, e acostumbrados de hechos de armas $\rangle^{116}$. Las crónicas lo corroboran: un comandante tenía que ser también un guerrero. De Rodrigo Manrique y Alonso de Monroy se decía que siempre eran los primeros en atacar al enemigo, así todos les seguirían y se volverían más osados ${ }^{117}$. El belicoso arzobispo de Toledo, Alfonso Carrillo de Acuña, también dirigía sus huestes, al igual que Iñigo López de Mendoza, «no como capitán, más como compañero» ${ }^{118}$. La debilidad de las estructuras de mando, derivadas de los mecanismos de reclutamiento, provocaba problemas de autoridad como los mencionados al inicio del apartado. John France señaló que una parte vital del «arsenal de persuasión» de un comandante era la valentía personal ${ }^{119}$. Así, si un líder pretendía

112 CHACÓN, 1940: 134-137. GARCÍA DE SANTA MARÍA, 1891: 297.

113 CHACÓN, 1940: 132-140. PULGAR, 2008, vol. I: 207-215. OROZCO y PARRA, 1978: 406. DÍAZ DE GAMES, 2005: 380 y 442. Jones defiende su valor incluso en el fragor de la batalla. Sostiene que los símbolos podían volverse ilegibles, con lo que el mando y control debía ejercerse mediante el uso de trompetas. JONES, 2015: 69-83.

114 «Bien saben los guerreros que todos miran a la bandera, tan bien los henemigos como los amigos; e si la veen retraer estando en la pelea, pierden los suyos el esfuerço, e cóbranlo los contrarios; e si la veen estar firme, o yr adelante, eso mesmo [...] Ca la bandera es como la facha en la sala, que alunbra a todos; e si se amata por alguna ocasión, todos quedan lóbregos e sin vista, [sc.] vençidos». DÍAZ DE GAMES, 2005: 380-381.

115 DÍAZ DE GAMES, 2005: 445-446. CHACÓN, 1940: 170-171. ENRÍQUEZ DEL CASTILLO, 1994: 278-279. VALERA, 1941: 129; 1927: 70-71. PULGAR, 2008, vol. 1: 213-214. PALENCIA, 1973, vol. 2: 271.

116 SÁNCHEZ-ARCILLA, 2004, Segunda Partida, Titulo XXIII, ley V.

117 PULGAR, 2007: 154. MALDONADO, 1978: 59.

118 GUILLÉN DE SEGOVIA, 1962: 42. PULGAR, 2007: 107.

119 FRANCE, 1999: 139-149. 
ser escuchado y seguido tenía que predicar con el ejemplo, aplicando lo que John Keegan denominó «liderazgo heroico» ${ }^{120}$.

No se puede obviar el hecho, empero, de que combatir en primera línea podía acarrear peligros evidentes. Rodrigo Ponce de León fue herido en su bautismo de fuego en el Madroño en 1462 y, cinco años más tarde, el arzobispo de Toledo, Alonso Carrillo, fue herido en el muslo en la segunda batalla de Olmedo ${ }^{121}$. El poeta Jorge Manrique tuvo peor suerte, pues murió en una escaramuza cerca del castillo de Garcimuñoz en $1479^{122}$. A pesar de que la tecnología defensiva había alcanzado su clímax con el arnés blanco del siglo XV, las heridas aún eran posibles y, aunque por sí mismas podían ser relativamente insignificantes, podían llegar a infectarse y volverse mortales. Así le ocurrió al infante Enrique, líder del partido de los Infantes de Aragón y comandante de la vanguardia que se enfrentó a Álvaro de Luna durante la primera batalla de Olmedo, en 1445. Una herida que tenía en la mano le provocó la muerte tras varios días de agonía ${ }^{123}$. Por ello, combatir en primera línea podía tener unas consecuencias desastrosas si el comandante moría o era apresado, especialmente si se trataba del rey ${ }^{124}$.

Tras la derrota y captura de Juan II en Poitiers en 1356, los escritores y cronistas franceses dejaron de valorar que un rey combatiera, como tradicionalmente se había hecho, pasando a tener en consideración otras cuestiones como la preparación y la estrategia ${ }^{125}$. En Castilla, sin embargo, imperaba una dualidad en la que se querían evitar riesgos, pero aún se apreciaba el liderazgo inspiracional. Durante las fases previas del asedio de Vélez-Málaga en 1487, Fernando el Católico se lanzó personalmente a recuperar un cerro que los musulmanes habían tomado. A pesar de que la acción fue un éxito, Pulgar menciona que los nobles presentes amonestaron al rey, recordándole que muchas «huestes fueron perdidas por la cayda de su rey». El monarca respondió que había visto a sus hombres sufrir el empuje granadino y «como buen capitán los socorría». Dos años más tarde, el mismo cronista señalaba la importancia de que el rey católico combatiera en una escaramuza durante el asedio de Baza, porque «la presençia del prínçipe mucho haze en las batallas, asy para

${ }^{120}$ KEEGAN, 2015: 80-119.

${ }^{121}$ CARRIAZO, 2003b: 165. ENRÍQUEZ DEL CASTILLO, 1994: 278. VALERA, 1941: 128.

122 PULGAR, 2008, vol. 1: 358.

123 ROSELL, 1953: 629. PALENCIA, 1998, vol. 1: 25.

124 MORILLO, 4 (Woodbridge, 2006): 71. El caso más conocido del «cuatrocientos» tal vez sea el de Ricardo III de Inglaterra. Cuando murió en la batalla de Bosworth (1485), todo su ejército se rindió ante el futuro Enrique VII. GOODMAN, 2006: 192.

${ }^{125} \mathrm{Su}$ sucesor, Carlos V, tomó buena nota de ello y jamás pisó un campo de batalla, lo que le valió que Christine de Pizan alabara su prudencia y valentía como líder militar. TAYLOR, 2013: 46-50. 
poner ánimo a los suyos, como para que el esforçado no quede sin ser galardonado, e el flaco no quede syn ser conosçido» ${ }^{126}$.

Ser un compañero de armas, además de un líder, podía volverse imperativo en conflictos internos, cómo señaló Christine de Pizan ${ }^{127}$. En este tipo de contiendas había más que demostrar que en otro tipo de enfrentamientos. En una sociedad como la medieval, en la que el honor era parte esencial de la idiosincrasia de los bellatores, el liderazgo heroico se volvía indispensable ${ }^{128}$. Las fuentes narrativas castellanas, en oposición a las portuguesas, presentan a Fernando el Católico en la batalla de Toro, en 1476, cabalgando entre sus tropas, esforzándolas, reforzando los puntos críticos y combatiendo cuando era necesario $^{129}$. Álvaro de Luna también conocía la importancia de liderar con el ejemplo. Además, tenía mucho que perder, pues siempre se jugó su propia posición como favorito del rey, por lo que se esforzó al máximo en todas las empresas militares en las que se vio envuelto. En la batalla de Olmedo del año 1445, a pesar de tener cincuenta y cinco años, dirigió la vanguardia de Juan II de Castilla, lo que le valió una herida de lanza en el muslo ${ }^{130}$.

En conclusión, desde la toma de decisiones estratégicas en los consejos hasta su aplicación táctica en el campo de batalla, los líderes de la Castilla cuatrocentista estaban limitados por los mecanismos sociales imperantes en la esfera militar. Aun así, los comandantes eran capaces de salvar las trabas inherentes a su oficio, confiando en el consejo de los veteranos y experimentados. Del mismo modo, las limitaciones tecnológicas y organizativas del periodo forzaron un liderazgo heroico que ponía en el centro del peligro a los comandantes. Solo así podía convertirse un ejército feudal en una máquina bélica perfectamente funcional.

\section{Conclusiones}

En la Castilla del siglo XV, como en otros reinos europeos, la configuración social instaba a que los líderes militares fueran los mismos que mandaban en la esfera política y socio-económica, situación que perduró incluso tras la creación de las Guardas de Castilla en 1493. La aristocracia terrateniente tenía

126 PULGAR, 2008, vol. 2: 266-267, 407.

127 PIZAN, 2003: 21-23.

${ }_{128}$ Rogers sostiene que liderar desde el frente era la forma que tenían los comandantes medievales para ser respetados. ROGERS, 2007: 186-188. Morillo incide en el aspecto psicológico, apuntando a un intento de mitigar la cobardía: los líderes combatían en primera línea para trasmitir valentía. MORILLO, 4 (Woodbridge, 2006): 68, nota 10.

129 PULGAR, 2008, vol. 1: 213. VALERA, 1927, 71.

130 En La Higueruela (1431) también combatió en primera línea, dirigiendo la delantera. CHACÓN, 1940: 137, 171.

Hispania, 2019, vol. LXXIX, nº 263, septiembre-diciembre, págs. 639-668, ISSN: 0018-2141, e-ISSN: 1988-8368 https://doi.org/10.3989/hispania.2019.015 
como función social la guerra y era la capa más alta de esa nobleza la que monopolizaba el mando militar, al que se accedía según criterios de extracción social y cercanía al rey. Si bien la segunda condición era de obligado cumplimiento, la primera no tenía por qué serlo, generando una distorsión en el sistema que podía derivar en indisciplina o desautorizaciones. La excepción más notable a la regla se observa en aquellos oficios de carácter temporal. Los capitanes de la frontera, en concreto, eran reclutados de entre la más alta nobleza, aunque se valoraban capacidades como la veteranía y la pericia. Las carencias del sistema se suplían, en parte, mediante la formación militar de la nobleza desde una edad temprana. Esta educación marcial, basada en la lectura, pero sobre todo en la transmisión oral y el aprendizaje práctico, buscaba instruir a los jóvenes aristócratas en el ejercicio del mando, para así disminuir las posibilidades de que un líder no se viera capaz de afrontar el reto de comandar.

Con todo, la fase formativa no siempre era suficiente para garantizar un liderazgo eficaz. Además, los filtros que podían establecerse mediante las capitanías de frontera no suponían más que una leve mejoría. Eran temporales y los capitanes ejercían el mando independiente siempre y cuando la hueste principal no estuviera operando en ese frente. En campaña, el ejército real estaba dirigido por los miembros de la alta nobleza. La ausencia de una estructura de mando estable tenía un impacto directo en el ejercicio del liderazgo que, agravado por las limitaciones tecnológicas, provocaba que los líderes se vieran reducidos a persuadir e inspirar. En consecuencia, los comandantes castellanos se vieron obligados en muchas ocasiones a dirigir sus tropas desde la primera línea de combate, exponiendo su propia integridad física. Lejos de ser aficionados inexpertos, los líderes militares de la Castilla del «cuatrocientos» fueron capaces de imponerse a las limitaciones inherentes al sistema y llevar a cabo hazañas militares como la conquista del reino de Granada. 
Anexo I. Capitanías de frontera según las fuentes narrativas: guerra contra Navarra y Aragón (1429-30) ${ }^{131}$

\begin{tabular}{|c|c|c|c|}
\hline Sector fronterizo & Capitán & Servicio & Tropas asignadas \\
\hline \multirow{2}{*}{$\begin{array}{c}\text { Frontera de } \\
\text { Navarra, desde } \\
\text { Haro hasta Alfaro }\end{array}$} & $\begin{array}{l}\text { Pedro de Velasco, } \\
\text { camarero mayor }\end{array}$ & $1429-1430$ & $\begin{array}{l}600 \text { lanzas y } \\
1.000 \text { peones }\end{array}$ \\
\hline & $\begin{array}{c}\text { Pedro de Zúñiga, conde de } \\
\text { Ledesma }\end{array}$ & 1430 & - \\
\hline $\begin{array}{l}\text { Frontera de Aragón, } \\
\text { base en Ágreda }\end{array}$ & $\begin{array}{l}\text { Iñigo López de Mendoza, } \\
\text { señor de Hita y Buitrago }\end{array}$ & $1429-1430$ & $\begin{array}{c}300 \text { lanzas y } 600 \\
\text { peones }\end{array}$ \\
\hline \multirow[b]{2}{*}{$\begin{array}{l}\text { Frontera con el } \\
\text { reino de Valencia, } \\
\text { base en Requena }\end{array}$} & $\begin{array}{l}\text { Fernando Álvarez de Toledo, } \\
\text { señor de Valdecorneja }\end{array}$ & $1429-1430$ & - \\
\hline & $\begin{array}{c}\text { Luis de Guzmán, maestre de } \\
\text { Calatrava } \\
\text { y } \\
\text { Diego de Ribera, adelantado } \\
\text { mayor de la Frontera }\end{array}$ & 1430 & - \\
\hline Reino de Murcia & $\begin{array}{c}\text { Alfonso Yáñez Fajardo, } \\
\text { adelantado de Murcia }\end{array}$ & $1429-1430$ & - \\
\hline
\end{tabular}

ANEXo II. Capitanías de frontera según las fuentes narrativas: guerra contra Granada $(1430-31)^{132}$

\begin{tabular}{|c|c|c|c|}
\hline Sector fronterizo & Capitán & Servicio & Tropas asignadas \\
\hline Obispado de Jaén & $\begin{array}{c}\text { Diego Gómez de Ribera, } \\
\text { adelantado mayor de la Frontera }\end{array}$ & $1430-1431$ & 500 lanzas \\
\hline $\begin{array}{c}\text { Arzobispados de } \\
\text { Sevilla y Córdoba, } \\
\text { base en Écija }\end{array}$ & $\begin{array}{c}\text { Fernando Álvarez de Toledo, } \\
\text { señor de Valdecorneja }\end{array}$ & $1430-1431$ & 500 lanzas \\
\hline $\begin{array}{c}\text { Jeréz de la } \\
\text { Frontera }\end{array}$ & $\begin{array}{c}\text { Pedro García de Herrera, } \\
\text { mariscal de Castilla }\end{array}$ & $1430-1431$ & 500 lanzas \\
\hline $\begin{array}{c}\text { Obispado de } \\
\text { Cartagena }\end{array}$ & $\begin{array}{c}\text { Alfonso Yáñez Fajardo, } \\
\text { adelantado de Murcia }\end{array}$ & $1430-1431$ & 500 lanzas \\
\hline
\end{tabular}

131 GARCÍA DE SANTA MARÍA, 1891: 114-115, 199. ROSELL, 1953: 465, 482-483.

132 GARCÍA DE SANTA MARÍA, 1891: 221. ROSELL, 1953: 487. 
Anexo III. Capitanías de frontera según las fuentes narrativas: guerra contra Granada (1431-39) $)^{133}$

\begin{tabular}{|c|c|c|c|}
\hline $\begin{array}{c}\text { Sector } \\
\text { fronterizo }\end{array}$ & Capitán & Servicio & Tropas asignadas \\
\hline \multirow{4}{*}{$\begin{array}{l}\text { Obispados de } \\
\text { Jaén y Córdoba }\end{array}$} & $\begin{array}{l}\text { Luis de Guzmán, maestre de } \\
\text { Calatrava }\end{array}$ & $1431-1432$ & 600 lanzas é jinetes \\
\hline & $\begin{array}{l}\text { Pedro Álvarez de Osorio, señor } \\
\text { de Villalobos y Castroverde }\end{array}$ & $1432-1433$ & - \\
\hline & $\begin{array}{l}\text { Fernando Álvarez de Toledo, } \\
\text { señor de Valdecorneja }\end{array}$ & $1434-1437$ & 600 lanzas \\
\hline & $\begin{array}{c}\text { Iñigo López de Mendoza, señor } \\
\text { de Hita y Buitrago }\end{array}$ & $1437-1439$ & - \\
\hline \multirow{4}{*}{$\begin{array}{l}\text { Arzobispado de } \\
\text { Sevilla }\end{array}$} & $\begin{array}{l}\text { Diego Gómez de Ribera, } \\
\text { adelantado mayor de Andalucía }\end{array}$ & $1431-1434$ & 500 lanzas é jinetes \\
\hline & $\begin{array}{l}\text { Gutiérrez de Sotomayor, } \\
\text { maestre de Alcántara }\end{array}$ & $1434-1436$ & - \\
\hline & $\begin{array}{l}\text { Pedro de Zúñiga, conde de } \\
\text { Ledesma }\end{array}$ & $1436-1438$ & - \\
\hline & $\begin{array}{l}\text { Juan de Guzmán, conde de } \\
\text { Niebla }\end{array}$ & $1438 / 1439$ & - \\
\hline
\end{tabular}

\section{Bibliografía}

Allmand, Christopher, The De re militari of Vegetius: the reception, transmission and legacy of a Roman text in the Middle Ages, Cambridge, Cambridge University Press, 2011.

Anglería, Pedro Mártir de, «Epistolario», en José López de Toro (ed.), Documentos inéditos para la Historia de España, IX, Madrid, Imprenta Góngora, 1953, vol. I.

Arias, Fernando, «Castile-Leon II. Late Middle Ages ( $14^{\text {th }}$ to $15^{\text {th }}$ centuries)», en Francisco García Fitz y João Gouveia Monteiro (eds.), War in the Iberian Peninsula, 700-1600, Nueva York, Routledge, 2018: 94-123.

133 GARCÍA DE SANTA MARÍA, 1891: 312, 371. ROSELL, 1953: 500, 512, 519, 547, 550. La información obtenida de las fuentes cronísticas ha sido complementada con los siguientes trabajos: GARCÍA, 5-6 (Cádiz, 1985-1986): 203-204. CARRIAZO, 2003a, 124. LÓPEZ DE COCA, 33/2 (Madrid, 2003): 643-666. 
Balenchana, Jose Antonio (ed.), Epístolas y otros varios tratados de Mosen Diego de Valera, Madrid, Imprenta Miguel Ginesta, 1878.

Beceiro, Isabel, «La Biblioteca del conde de Benavente a mediados del siglo XV y su relación con las mentalidades y usos nobiliarios de la época», En la España medieval, 2 (Madrid, 1982): 135-146.

Beceiro, Isabel, Libros, lectores y bibliotecas en la España Medieval, Murcia, Nausícaä, 2007.

Beceiro, Isabel y Franco, Alfonso, «Cultura nobiliar y bibliotecas. Cinco ejemplos, de las postrimerías del siglo XIV a mediados del XVI», Historia, Instituciones, Documentos, 12 (Sevilla, 1986): 277-350.

Beeler, John H., «Towards a Re-Evaluation of Medieval English Leadership», Journal of British Studies, 3 (Cambridge, 1963): 1-10.

Bell, Adrian R., Curry, Anne, King, Andy y Simpkin, David, The soldier in Later Medieval England, Nueva York, Oxford University Press, 2013.

Bernáldez, Andrés, Memorias del reinado de los Reyes Católicos, edición de Manuel Gómez-Moreno y Juan de Mata Carriazo, Madrid, Real Academia de la Historia, 1962.

Bouvet, Honoré de, Árbol de las batallas, Madrid, Ministerio de Defensa, 2008.

Caferro, William, John Hawkwood: An english mercenary in fourteenth-century Italy, Baltimore, John Hopkins University Press, 2005.

Carriazo, Juan de Mata (ed.), Hechos del condestable Don Miguel Lucas de Iranzo, Granada, Universidad de Granada, 2009.

Carriazo, Juan Luis, La Casa de Arcos entre Sevilla y la frontera de Granada (13741474), Sevilla, Universidad de Sevilla, 2003a.

Carriazo, Juan Luis (ed.), Historia de los hechos del Marqués de Cádiz, Granada, Universidad de Granada, 2003 b.

Carrillo de Huete, Pedro, Crónica del Halconero de Juan II, edición de Juan de Mata Carriazo, Granada, Universidad de Granada, 2006.

Chacón, Gonzalo (atribuida), Crónica de don Álvaro de Luna, condestable de Castilla, maestre de Santiago, edición de Juan de Mata Carriazo, Madrid, EspasaCalpe, 1940.

Contamine, Philippe, Guerre, état et société à la fin du Moyen Âge. Études sur les armées des rois de France, 1337-1494, París, Mouton, 1972.

Contamine, Philippe, La guerra en la Edad Media, Barcelona, Labor, 1984.

Delbrück, Hans, History of the Art of War. III: Medieval Warfare, Lincoln, University of Nebraska Press, 1982.

DeVries, Kelly, Joan of Arc: A Military Leader, Stroud, Sutton, 1999.

DeVries, Kelly, «The use of Chronicles in recreating Medieval Military History», Journal of Medieval Military History, 2 (Woodbridge, 2004): 1-15.

Díaz de Games, Gutierre, El Victorial, edición de Rafael Beltrán, Madrid, Taurus, 2005.

Enríquez del Castillo, Diego, Crónica de Enrique IV, edición de Aureliano Sánchez, Valladolid, Universidad de Valladolid, 1994.

Fernández de Larrea, Jon Andoni, El precio de la sangre: ejércitos y sociedad en Navarra durante la Baja Edad Media (1259-1450), Madrid, Sílex, 2013. 
Fradejas, José Manuel, La versión castellana medieval de la «Epitoma Rei Militaris», San Millán de la Cogolla, Cilengua, 2014.

France, John, Western warfare in the age of the Crusades, Nueva York, Cornell University Press, 1999.

García, María del Mar, «Jerez en las relaciones castellano-nazaríes. Aportación humana y económica en 1436», Estudios de historia y de arqueología medievales, 5-6 (Cádiz, 1985-1986): 191-204.

García, Michel (ed.), Crónica del rey Juan II de Castilla, Salamanca, Universidad de Salamanca, 2017.

García de Santa María, Álvar, «Crónica de Juan II de Castilla», en Colección de documentos inéditos para la historia de España, vol. $C$, edición de Antonio Paz y Meliá, Madrid, 1891.

García Fitz, Francisco, «La didáctica militar en la literatura castellana (segunda mitad del siglo XIII y primera del XIV)», Anuario de Estudios Medievales, 19 (Barcelona, 1989): 271-284.

García Fitz, Francisco, Castilla y León frente al Islam: Estrategias de expansión y tácticas militares (siglos XI-XIII), Sevilla, Universidad de Sevilla, 1998.

García Fitz, Francisco, «El Cid y la guerra», en César Fernández (coord.), El Cid, poema e historia. Actas del Congreso Internacional, Burgos, Ayuntamiento de Burgos, 2000: 383-418.

García Fitz, Francisco, «Las Navas de Tolosa y el paradigma bélico medieval», en Carlos Estepa y María Antonia Carmona (coords.), La Península Ibérica en tiempos de las Navas de Tolosa, Madrid, SEEM, 2014: 17-52.

García Fitz, Francisco, «Las guerras del rey Fernando», en Antonio-Miguel Bernal (coord.), Fernando el Católico, rey, Madrid, Marcial Pons, 2016: 47-71.

Gillingham, John, «Richard I and the Science of War in the Middle Ages», en Matthew Strickland (ed.), Anglo-Norman Warfare. Studies in late Anglo-Saxon and AngloNorman military organization and warfare, Woodbridge, Boydell, 1992a: 194-207.

Gillingham, John, «William the Bastard at War», en Matthew Strickland (ed.), AngloNorman Warfare. Studies in late Anglo-Saxon and Anglo-Norman military organization and warfare, Woodbridge, Boydell, 1992b: 143-160.

Goodman, Anthony, The Wars or the Roses. The Solder's Experience, Stroud, Tempus, 2006.

Guillén de Segovia, Pedro, La gaya ciencia, edición de O. J. Tuulio y J. M. Casas, Madrid, CSIC, 1962.

Hamilton, Bernard, «Baldwin the Leper as War Leader», en Alan V. Murray (ed.), From Clermont to Jerusalem: The Crusades and Crusader Society, 1095-1500, Turnhout, Brepols, 1998: 119-130.

Hay, David J., The military leadership of Matilda of Canossa, 1046-1115, Manchester, Manchester University Press, 2010.

Hosler, John D., «The War Councils and Military Advisers of Louis VII of France», en Michael L. Bardot y Laurence W. Marvin, Louis VII and His World, Leiden, Brill, 2018: 11-28.

Jiménez, Juan Francisco, «Adelantados y mando militar: los Fajardo en Murcia (siglos XV-XVI)», en La organización militar en los siglos XV y XVI, Málaga, Cátedra General Castaños, 1993: 151-157. 
Jones, Robert W., Bloodied banners. Martial display on the medieval battlefield, Woodbridge, Boydell, 2015.

Kagay, Donald J., «Battle-Seeking Commanders in the Later Middle Ages: Phases of Generalship in the War of the Pedros», en L. J. Andrew Villalon y Donald J. Kagay, The Hundred Years War (Part III). Further Considerations, Leiden, Brill, 2013: 63-84.

Keegan, John, La Máscara del Mando, Madrid, Turner, 2015.

Ladero, Miguel Ángel, «De Per Afán a Catalina de Ribera. siglo y medio en la historia de un linaje sevillano (1371-1514)», En la España medieval, 4 (Madrid, 1984): 447-498.

Lafuente, Mario, Un reino en armas. La guerra de los Dos Pedros en Aragón, Zaragoza, Institución Fernando el Católico, 2014

Lawrence, Jeremy, «Nueva luz sobre la biblioteca del Conde de Haro: inventario de 1455», El Crotalón: Anuario de filología española, 1 (Madrid, 1984): 1073-1111.

Liddell Hart, Basil H., La estrategia de aproximación indirecta (Las guerras decisivas de la Historia), Barcelona, Atalaya, 1946.

López de Coca, José Enrique, «Fernando Álvarez de Toledo, Capitán de la frontera de Jaén», Anuario de estudios medievales, 33/2 (Barcelona, 2003): 643-666.

Macdonald, Alastair J., "Triumph and Disaster. Scottish Military Leadership in the Later Middle Ages», en Andy King y David Simpkin, England and Scotland at War, c.1296-c.1513, Leiden, Brill, 2012: 255-282.

Maldonado, Alonso de, Vida e historia del maestre de Alcántara, don Alonso de Monroy, edición de Leonardo Romero, Tarragona, Tarraco, 1978.

Mallett, Michael, Mercenaries and their masters. Warfare in Renaissance Italy, Londres, The Bodley Head, 1974.

Martínez Sopena, Pascual (coord.), «Liderazgo y linaje nobiliario en la Península Ibérica (siglos XII-XV)», Studia Zamorensia, 12 (Zamora, 2013).

Martins, Miguel Gomes y Monteiro, João Gouveia, «Portugal II. The Late Middle Ages 1249-1367: A time of reforms and royal consolidation», en Francisco García Fitz y João Gouveia Monteiro (eds.), War in the Iberian Peninsula, 700-1600, Nueva York, Routledge, 2018: 212-241.

Marvin, Laurence W., «Medieval and Modern $\mathrm{C}^{2}$ : Command and Control in the Field during Western Europe's Long Twelfth Century (1095-1225)», War \& Society, 35/3 (Sidney, 2016): 152-176.

Marvin, Laurence W., «King Louis VII as General on the Second Crusade: A Failure of Command, Control and Communication», en Michael L. Bardot y Laurence W. Marvin, Louis VII and His World, Leiden, Brill, 2018: 29-49.

Mas, Andrés, «La formación militar del Rey Católico», en La organización militar en los siglos XV y XVI, Málaga, Cátedra General Castaños, 1993: 379-380.

Monteiro, João Gouveia, A guerra em Portugal nos finais da idade média, Lisboa, Notícias, 1998.

Monteiro, João Gouveia, Martins, Miguel Gomes y Faria, Tiago Viúla de, «Another 1415: Portugal's military landscape at the time of Agincourt», Journal of Medieval History, 43 (Ámsterdam, 2017): 118-135.

Morillo, Stephen, «Expecting Cowardice: Medieval Battle Tactics Reconsidered», Journal of Medieval Military History, 4 (Woodbridge, 2006): 65-73. 
Oman, Charles, The Art of War in the Middle Ages. A.D. 378-1515, Londres, Cornell University Press, 1953.

Oman, Charles, A history of the art of war in the Middle Ages, Londres, Greenhill Books, 1991.

Orozco, Pedro de y Parra, Juan de la, [Primera] Historia de la Orden de Santiago, edición de Antonio Vargas-Zúñiga, Badajoz, Institución Pedro de Valencia, 1978.

Palencia, Alfonso de, Gesta Hispaniensia ex annalibus suorum dierum collecta, edición de Brian Tate, Lawrence/Madrid, Jeremy/RAH, 1998.

Palencia, Alonso de, Crónica de Enrique IV, edición de Antonio Paz y Meliá, Madrid, Atlas, 1973.

Pina, Rui de, Crónica de D. Afonso V, edición de M. Lopes de Almeida, Oporto, Lello \& Irmão, 1977.

Pizan, Christine de, The Book of Deeds of Arms and of Chivalry, edición de Charity C. Willard, traducción de Sumner Willard, Pennsylvania, Pennsylvania State University Press, 2003.

Prestwich, Michael, Armies and Warfare in the Middle Ages, New Haven/Londres, Yale University Press, 1996.

Pulgar, Fernando del, Claros varones de Castilla, edición de Miguel Ángel Pérez, Madrid, Cátedra, 2007.

Pulgar, Fernando del, Crónica de los Reyes Católicos, edición de Juan de Mata Carriazo, Granada, Universidad de Granada, 2008, 2 vols.

Roca, María Elvira, Tratado militar de Frontino: humanismo y caballería en el cuatrocientos castellano. Traducción del siglo XV, Madrid, CSIC, 2010.

Rodríguez, Jesús D., El debate sobre la caballería en el siglo XV: la tratadística caballeresca castellana en su marco europeo, Valladolid, Junta de Castilla y León, 1996.

Rogers, Clifford J., «The Bergerac Campaign (1345) and the Generalship of Henry of Lancaster», Journal of Medieval Military History, 2 (Woodbridge, 2004): 89-110.

Rogers, Clifford J., Soldiers' lives through History: The Middle Ages, Wesport, Greenwood Press, 2007.

Rojas, Manuel, «En torno al 'liderazgo' nobiliario en la frontera occidental granadina durante el siglo XV», Historia. Instituciones. Documentos, 20 (Sevilla, 1993): 499-522.

Rojas, Manuel, «La capacidad militar de la nobleza en la frontera con Granada. El ejemplo de don Juan Ponce de León, II conde de Los Arcos y señor de Marchena», Historia. Instituciones. Documentos, 22 (Sevilla, 1995): 497-532.

Rosell, Cayetano (ed.), «Crónica de Juan II», en Crónicas de los Reyes de Castilla, Madrid, Atlas, 1953, vol. II.

Sáiz, Jorge, Caballeros del rey. Nobleza y guerra en el reinado de Alfonso el Magnánimo, Valencia, Universidad de Valencia, 2008.

Schiff, Mario, La bibliothèque du Marquis de Santillane, París, Émile Bouillon, 1905.

Shahar, Shulamith, Childhood in the Middle Ages, Londres, Routledge, 1992.

Simpkin, David, The English Aristocracy at War. From the Welsh Wars of Edward I to the Battle of Bannockburn, Woodbridge, Boydell, 2008.

Smail, Raymond C., Crusading Warfare, 1097-1193, Cambridge, Cambridge University Press, 1996. 
Sánchez-Arcilla, José (ed.), Las Siete Partidas (El libro del Fuero de las leyes), Madrid, Reus, 2004.

Sánchez-Parra, María Pilar (ed.), Crónica Anónima de Enrique IV de Castilla 14541474, Madrid, Ediciones de la Torre, 1991.

Stewart, Paul, «Military command and the development of the viceroyalty under Ferdinand and Isabella», Journal of Medieval and Renaissance Studies, 5 (Los Ángeles, 1975): 223-242.

Suárez, Luis, Fernando el Católico, Barcelona, Ariel, 2004.

Taylor, Craig, Chivalry and the ideals of knighthood in France during the Hundred Years War, Cambridge, Cambridge University Press, 2013.

Valera, Diego de, Crónica de los Reyes Católicos, edición de Juan de Mata Carriazo, Madrid, Revista de Filología Española, 1927.

Valera, Diego de, Memorial de diversas hazañas, edición de Juan de Mata Carriazo, Madrid, Espasa-Calpe, 1941.

Verbruggen, Jan F., The Art of Warfare in Western Europe during the Middle Ages from the Eighth Century to 1340, Woodbridge, Boydell, 1997.

Villacorta, María Consuelo (ed.), Libro de las buenas andanças e fortunas que fizo Lope García de Salazar, Bilbao, UPV/EHU, 2015.

Villalon, L. J. Andrew, «Battle-Seeking, Battle-Avoiding, or perhaps just Battle-Willing? Applying the Gillingham Paradigm to Enrique of Castile», Journal of Medieval Military History, 8 (Woodbridge, 2010): 131-54.

Recibido: 06/09/2018

Aceptado: 07/05/2019

Hispania, 2019, vol. LXXIX, n 263 , septiembre-diciembre, págs. 639-668, ISSN: 0018-2141, e-ISSN: 1988-8368 https://doi.org/10.3989/hispania.2019.015 